\title{
Current Status of Magnetic Resonance on Saliva for Oral and Dental Health Early Diagnosis
}

\author{
Anastasia Katsavochristou $1, * \mathbb{B}$ and Dimitrios Koumoulis ${ }^{2, *}$ \\ 1 Division of Prosthodontics, University of Kentucky College of Dentistry, Lexington, KY 40536, USA \\ 2 Center for Applied Energy Research, University of Kentucky, Lexington, KY 40511, USA \\ * Correspondence: anastasia.katsavochristou@uky.edu (A.K.); dimitrios.koumoulis@uky.edu (D.K.)
}

Received: 12 March 2020; Accepted: 9 April 2020; Published: 15 April 2020

\begin{abstract}
Magnetic resonance spectroscopy of biomolecules has recently gained attention for clinical diagnosis. Its combination with saliva collection and analysis can promote early disease detection and monitoring, by identifying biomarkers of specific underlying pathology or disease as detected in saliva. With this novel, non-invasive technique, certain salivary biomarkers have been linked to dental and periodontal tissues pathology, as well as to specific head and neck cancer malignancies. At present, diagnostic biomarkers are still in need for further identification (e.g., diagnosis and monitoring of Sjögren's syndrome), and nuclear magnetic resonance spectroscopy has been found to be a promising technique to compliment the current analytic methodology. Moreover, this article reports on the various data collection and analysis parameters used in the literature. Protocol standardization is yet to be established not only for the laboratory procedures, but also for the clinical sample collection. Herein, we review the current status of utilizing nuclear magnetic resonance in order to further support data on health associated biomarkers, and we also propose a saliva sampling scheduling protocol with the potential to be used in the clinical and experimental setting for standardization of the testing methodology.
\end{abstract}

Keywords: metabolomics; biomarkers; salivaomics; caries; periodontics; oral cancer

\section{Introduction-Saliva Testing}

A multitude of clinical and laboratory testing is included in the medical sciences, both invasive and non-invasive. The non-invasive techniques are of paramount importance. They not only eliminate potential risks to the patient arising from the testing procedure itself, but also eliminate patient discomfort. The latter increases patient compliance, which is an absolute prerequisite for timely diagnosis and therapy, as the discomfort of a testing procedure itself often results in avoidance, and thus diagnosis and treatment delay. The importance of early detection and timely diagnosis has been greatly emphasized in health sciences, as it has an immediate and substantial effect on the therapeutic effectiveness and outcome.

Saliva, as the medium for clinical testing, presents unique advantages. The sample collection is not only non-invasive, but also easy, immediate, and fast without the need for any expensive or complex instrumentation or advanced training. In addition, it is possible to be repeated multiple times [1,2]. As a result, it is suitable not only for a one-time testing, but also for continuous monitoring if deemed medically necessary. Moreover, saliva sampling collection can be easily performed in various clinical settings, from dental and family medicine clinics to any hospital setting. Because of its ease and swiftness, it can be performed during routine health appointments, without the need for additional or specialized appointments. Under established protocols and guidelines, saliva sampling offers the potential to further become available for non-clinical settings, for distant sites, or even as a self-sampling at-home kit. This increased accessibility would further promote early timing of detection 
of an underlying condition, even when no symptoms have yet appeared. Consequently, health will be substantially promoted by reducing the incidence of undiagnosed conditions that lay undetected until they have progressed to an advanced stage with devastating health results.

Saliva includes information regarding not only the local environment (oral), but also the general health (systemic conditions). The information is included in organic and inorganic biomarkers. The specificity and sensitivity of the biomarkers is important in order to be able to distinguish between physiologic functions and underlying conditions. The biomarkers' information, as related to health and disease, can be found and interpreted through proteomics, transcriptomics, microRNAomics, microbiomics, and metabolomics analysis [2].

Magnetic resonance analysis of saliva has identified significant biomarkers correlated with oral, dental, and periodontal pathology, as well as salivary biomarkers linked to the presence of head and neck squamous cell carcinoma and sarcoidosis. Interestingly, salivary biomarkers have been also used in order to verify and monitor established health after therapy of the pathology [3-15].

\section{The Role of Nuclear Magnetic Resonance in Saliva Testing and Analysis}

Salivary biomolecules have gained a lot of attention worldwide in the area of proteomics. Salivary proteome data have been made available to the research community though the Human Salivary Proteome Wiki (HSPW), a web portal supported by the National Institute of Dental and Craniofacial Research (NIDCR) of the National Institutes of Health (NIH) [16]. At the moment, the published HSPW data have been detected through two experimental techniques-mass spectrometry or gel electrophoresis. Liquid or gas chromatography along with mass spectrometry have been widely used for proteomic analysis. These techniques are based on the mass-to-charge ratio of the ions in the sample after separation of the compounds via chromatography [17]. Nuclear magnetic resonance (NMR) is an alternative and/or complimentary analytical method of great potential for the detection and analysis of biomarkers that are present in saliva, at the atomic level. Probing and characterization at the atomic level is of high importance for salivaomics, as it was recently observed that information in saliva is not only found in locally-produced molecules, but also carried from distant tissues through nano-vesicles [18]. NMR, as a powerful analytical method, can identify and quantitively analyze organic acids, amino acids, fatty acids, amines, and alcohol in the provided biofluid sample. Until now, it has been mainly employed for the analysis of plasma and urine [19].

In general, NMR as local probe exhibits an enhanced site-sensitivity and accuracy in the characterization of samples in almost all forms (gas, liquid, and solid state). NMR characterization of biofluids/biomolecules (e.g., saliva, urine, human blood plasma) and biomaterials (e.g., metals, ceramics, polymers) is a well-established method [20]. There are two principal advantages that have established NMR spectroscopy (especially solution-state NMR) as one of the most widely used characterization techniques. These include the small amount of sample needed compared with other volume average techniques, as well as the swiftness of the experimental data acquisition that can be performed in as fast as a few minutes [21]. The amount of saliva supernatant used for NMR analysis ranged from 0.17 to $0.60 \mathrm{~mL}$ (Table 1A) [3-15]. A saliva sample does not need any complex pre-treatment or preparation for the solution state NMR analysis to be performed [17]. Specifically, the NMR saliva sample preparation consists of centrifugation, and subsequent addition of a NMR solvent, standard, and buffer to the supernatant inside an NMR tube [3-14]. On the contrary, the more popular mass spectroscopic analysis requires multiple and more complex sample preparation steps (e.g., extraction, purification, digestion, separation), as well as costly labelling reference compounds for data acquisition and analysis. In this respect, NMR is less time-consuming and more cost-effective for data acquisition. Notably, the general NMR inherent insensitivity compared with mass spectroscopy can be improved using multiple scans, cryoprobes, and higher magnetic fields [22,23]. Regarding the current status of NMR in saliva metabolite analysis, it has been found to be underutilized compared with its potential, and a standardized protocol needs to be followed for its saliva analysis application [17,19]. 


\section{NMR Saliva Analysis in Dental Health-Application and Methodology}

\subsection{Dental Caries}

NMR has been found to be able to accurately detect the presence of dental caries in the pediatric oral cavity, by analyzing the presence and quantity of the corresponding metabolites in the saliva and comparing it to control samples (non-caries saliva samples). The organic and inorganic metabolites that are evaluated are based on the Human Metabolome Database. In this study, a $400 \mathrm{MHz}$ Bruker Avance spectrometer was used with a CPMG (Carr-Purcell-Meiboom-Gill) pulse sequence and T2 filter in order to suppress signals from other macromolecules, such as proteins (Table 1). On the basis of the NMR data, caries profile was correlated to increased levels of four metabolites (lactate, fatty acid, acetate, butyrate, an ambiguous component) and decreased levels of three other metabolites (phenylalanine, propionate, saccharides) [6]. In a following study, the authors investigated the possibility of evaluating the efficacy of dental caries treatment via saliva NMR analysis before and after treatment, focusing on the previously identified metabolites [6], with promising results [5].

In a more recent proton NMR ( $\left.{ }^{1} \mathrm{H}-\mathrm{NMR}\right)$ study, caries profile of children was correlated to alteration in the expression of 21 saliva metabolites [24]. Regarding the saliva collection methodology, passive drool was recommended instead of swab applicators for saliva collection, as the latter altered the NMR metabolomic results. However, no significant difference was found between unstimulated saliva and stimulated saliva by mastication on paraffin wax pellets for 3-5 $\mathrm{min}$ [24]. The avoidance of swab applicators or substances used as stimulants has been previously recommended in order to eliminate any alteration of the sample from the applicators and substances used [25].

Interestingly, an attempt was recently made to evaluate the oral health of mothers and their infants (0-28 months old) during the breastfeeding period via clinical examination accompanied by the saliva analysis. The NMR spectra presented distinct differences between infants without and with teeth (older than six months). The latter presented increased levels of multiple metabolites (Table 1B) [4].

\subsection{Periodontal Disease}

The periodontal disease involves the periodontium, which is specialized soft tissue that surrounds the teeth and connects them to the underlying bone structure. The disease can be chronic, with bacteria playing a primary role. It involves inflammation and potential subsequent destruction of the periodontium and osseous tissues.

NMR clinical studies on salivary profile observed discriminant metabolites that can differentiate between oral health and chronic generalized periodontitis [11,12], with a reported $91.1 \%$ sensitivity, $79.4 \%$ specificity, and $84.1 \%$ predictive accuracy [12]. Similar observations were reported by recent ${ }^{1} \mathrm{H}-\mathrm{NMR}$ metabolome studies that compared saliva samples from controls (oral health) and from two types of active periodontal disease (chronic and aggressive). NMR on saliva was found to be able to distinguish with satisfactory predictability between healthy and active disease samples. Hence, the establishment of a metabolomic profile for periodontal disease is being attempted (Table 1B) $[9,10]$. However, the metabolic analysis of the patients did not distinguish between the two different types of periodontal disease [9].

In addition, NMR analysis has been used in order to compare the metabolic changes after periodontal therapy $[7,8]$. This shows a great potential for collecting additional information regarding the effectiveness of current treatment protocols on an individual basis, as well as correlating metabolic changes during tissue repair. The salivary profile of the patients as measured after the periodontal therapy was found to be similar to the healthy subjects (Table 1B) [7]. 
Table 1. (A) Methodology of nuclear magnetic resonance (NMR) saliva experiments and (B) significant metabolites reported per diagnosis.

(A)

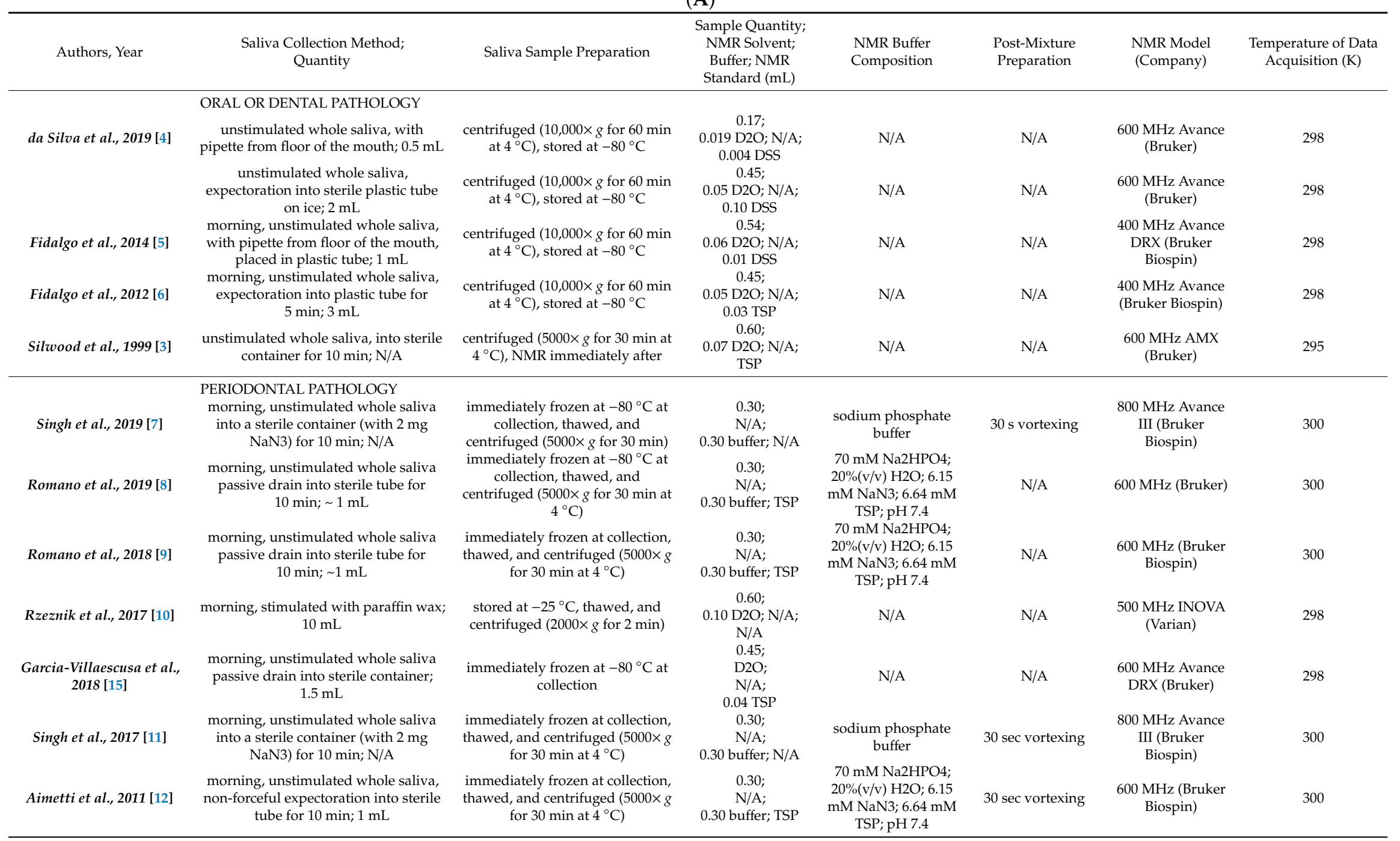


Table 1. Cont.

\begin{tabular}{|c|c|c|c|c|c|c|c|}
\hline Authors, Year & $\begin{array}{l}\text { Saliva Collection Method; } \\
\text { Quantity }\end{array}$ & Saliva Sample Preparation & $\begin{array}{l}\text { Sample Quantity; } \\
\text { NMR Solvent; } \\
\text { Buffer; NMR } \\
\text { Standard (mL) }\end{array}$ & $\begin{array}{l}\text { NMR Buffer } \\
\text { Composition }\end{array}$ & $\begin{array}{l}\text { Post-Mixture } \\
\text { Preparation }\end{array}$ & $\begin{array}{l}\text { NMR Model } \\
\text { (Company) }\end{array}$ & $\begin{array}{l}\text { Temperature of Data } \\
\text { Acquisition (K) }\end{array}$ \\
\hline Mikkonen et al., 2018 [13] & $\begin{array}{l}\text { OTHER CONDITIONS } \\
\text { morning, unstimulated whole saliva, } \\
\text { passive drain into sterile glass cup for } \\
\qquad 5 \mathrm{~min} ; \sim 5 \mathrm{~mL}\end{array}$ & $\begin{array}{l}\text { centrifuged }(14,000 \mathrm{rpm} \text { for } \\
6 \mathrm{~min}) \text {, stored at }-20^{\circ} \mathrm{C}\end{array}$ & $\begin{array}{c}0.45 ; \\
\text { D2O; } \\
0.05 \text { buffer; TSP }\end{array}$ & $\begin{array}{c}1.5 \mathrm{M} \mathrm{KH} 2 \mathrm{PO} 4 \\
2 \mathrm{mM} \mathrm{NaN3} ; 5.8 \mathrm{mM} \\
\text { TSP; D2O; pH 7.4 }\end{array}$ & $\begin{array}{c}\text { centrifuged } \\
10,000 \times g \text { for } 5 \text { min } \\
\text { at } 4{ }^{\circ} \mathrm{C}\end{array}$ & $\begin{array}{l}600 \mathrm{MHz} \text { Avance } \\
\text { III HD (Bruker) }\end{array}$ & $\begin{array}{l}\text { sample preheated to } \\
298,30 \text { min prior } \\
\text { acquisition }\end{array}$ \\
\hline $\begin{array}{l}\text { Duchemann et al., } 2016 \\
\text { [14] }\end{array}$ & stimulated; N/A & stored at $-20^{\circ} \mathrm{C}$ & $\begin{array}{l}0.60 ; \\
0.10 \mathrm{D} 2 \mathrm{O} ; \mathrm{N} / \mathrm{A} ; \\
\text { N/A }\end{array}$ & N/A & N/A & $\begin{array}{l}500 \text { MHz INOVA } \\
\text { (Varian) }\end{array}$ & 298 \\
\hline \multicolumn{8}{|c|}{ (B) } \\
\hline Authors, Year & Diagnosis & $\begin{array}{l}\text { Univariate Analysis: } \\
\text { Increased Metabolites }\end{array}$ & $\begin{array}{l}\text { Univariate Analysis: } \\
\text { Decreased Metabolites }\end{array}$ & \multicolumn{2}{|c|}{$\begin{array}{c}\text { Multivariate Analysis: Increased } \\
\text { Metabolites }\end{array}$} & \multicolumn{2}{|c|}{$\begin{array}{c}\text { Multivariate Analysis: Decreased } \\
\text { Metabolites }\end{array}$} \\
\hline & ORAL OR DENTAL PATHOLOGY & & & \multirow{3}{*}{\multicolumn{2}{|c|}{$\begin{array}{l}\text { Dentate vs. Edentulous: lactate, ethanol, } \\
\text { acetate, propionate, } \\
\text { n-butyrate, } \\
\text { n-acetyl sugars } \\
\text { propionate, } \\
\text { n-butyrate, lactate, ethanol, propionate, } \\
\text { n-acetyl sugar }\end{array}$}} & \multirow{2}{*}{\multicolumn{2}{|c|}{ Dentate vs. Edentulous: sugars }} \\
\hline da Silva et al., 2019 [4] & $\begin{array}{c}\text { Breastfeeding infants: Dentate (6 } \\
\text { mo+) vs. Edentulous; } \\
\text { Oral Candidiasis, Bohn Nodules }\end{array}$ & N/A & N/A & & & & \\
\hline & $\begin{array}{l}\text { Breastfeeding mothers: } \\
\text { Caries; Gingivitis }\end{array}$ & N/A & $\mathrm{N} / \mathrm{A}$ & & & & N/A \\
\hline Fidalgo et al., 2014 [5] & $\begin{array}{l}\text { Pediatric Caries vs. } \\
\text { 3-month-post-tx }{ }^{1}\end{array}$ & N/A & N/A & \multirow{3}{*}{\multicolumn{2}{|c|}{$\begin{array}{l}\text { Caries vs. Control: } \\
\text { acetate, butyrate, propionate, } \\
\text { fatty acids } \\
\text { lactate, fatty acid, acetate, butyrate } \\
\text { no control/comparison }\end{array}$}} & \multirow{3}{*}{\multicolumn{2}{|c|}{$\begin{array}{c}\text { 3-month-post-tx }{ }^{1} \text { vs. Caries: } \\
\text { saccharides, acetate, butyrate, } \\
\text { propionate, fatty acids } \\
\text { phenylalanine, propionate, saccharide } \\
\text { N/A }\end{array}$}} \\
\hline Fidalgo et al., 2012 [6] & Pediatric Caries & N/A & N/A & & & & \\
\hline Silwood et al., 1999 [3] & Root Caries & N/A & N/A & & & & \\
\hline & PERIODONTAL PATHOLOGY & & & \multirow{2}{*}{\multicolumn{2}{|c|}{$\begin{array}{l}\text { Perio vs. post-perio } \mathrm{sx}^{2} \text { : glutamate, } \\
\text { lactate, succinate, ethane sulfonate, } \\
\text { fucose, proline, ethanol } \\
\text { Control vs. post-perio sx }{ }^{2} \text { : lactate, } \\
\text { ethane sulfonate, ethanol }\end{array}$}} & \multirow{2}{*}{\multicolumn{2}{|c|}{$\begin{array}{l}\text { Perio vs. post-perio sx }{ }^{2} \text { : pyruvate. } \\
\text { Control vs. post-perio sx }{ }^{2}: \\
\text { alanine, glutamate }\end{array}$}} \\
\hline Singh et al., 2019 [7] & $\begin{array}{l}\text { Chronic Periodontitis vs. } \\
\text { post-tx } x^{1}\end{array}$ & N/A & N/A & & & & \\
\hline Romano et al., 2019 [8] & $\begin{array}{c}\text { Generalized Chronic } \\
\text { Periodontitis (GCP) vs. } \\
\text { post-non-surgical tx }{ }^{1}(\mathrm{GCP} x)\end{array}$ & N/A & N/A & \multicolumn{2}{|c|}{ no significance at baseline vs. after $t^{1}{ }^{1}$} & \multicolumn{2}{|c|}{ N/A } \\
\hline Romano et al., 2018 [9] & $\begin{array}{c}\text { Generalized Chronic } \\
\text { Periodontitis (GCP); Generalized } \\
\text { Aggressive Periodontitis (GAgP) }\end{array}$ & N/A & N/A & \multicolumn{2}{|c|}{$\begin{array}{l}\text { GCP vs. Control: proline, phenylalanine, } \\
\text { isoleucine, valine, tyrosine. } \\
\text { GAgP vs. Control: formate, } \\
\text { phenylalanine, tyrosine. } \\
\text { GCP vs. GAgP: no significant } \\
\text { discrimination }\end{array}$} & \multicolumn{2}{|c|}{$\begin{array}{l}\text { GDP vs. Control: pyruvate, } \\
\text { N-acetyl groups, lactate. } \\
\text { GAgP vs. Control: pyruvate, } \\
\text { N-acetyl-groups, lactate, sarcosine }\end{array}$} \\
\hline
\end{tabular}


Table 1. Cont.

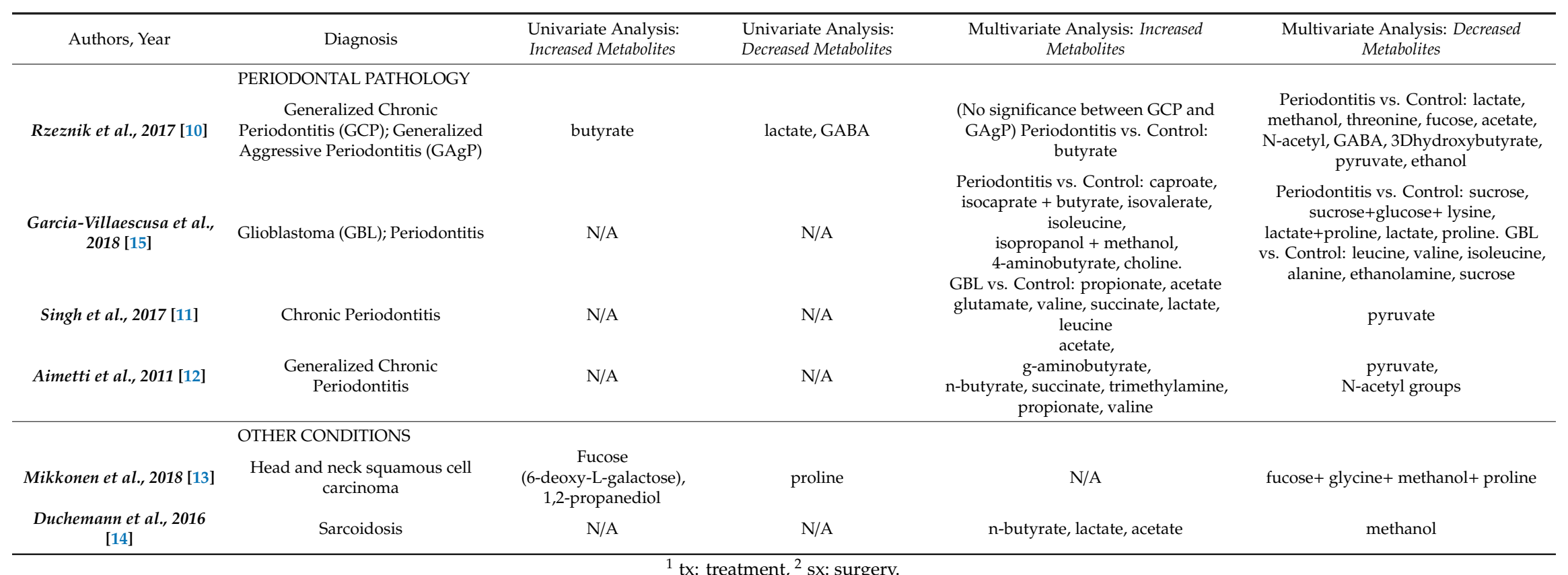

${ }^{1}$ tx: treatment, ${ }^{2}$ sx: surgery. 


\section{NMR Saliva Analysis in Oral Oncology}

Early detection in oncology cannot be emphasized enough [26]. Detection and diagnosis of a malignancy in an early stage significantly improves not only the survival of the patient, but also the quality of life after the elected therapy [27]. The quality of life should be considered of even equal significance with survival, as the treatment of a tumor can result in devastating physical and psychological circumstances for the patient that affects it immensely.

Unfortunately, tumors may lie undetected for a long period of time. The detection depends on the nature and presentation of symptomatology. It is influenced by various factors, such as the type, stage, location, and behavior of the tumor. The longer a tumor stays undetected and advances in staging, the more 'aggressive' the treatment modality may be in order for survival and decrease of the rate of recurrences [28]. Tumor invasion in critical structures, surgical resection of anatomic structures in order to provide tumor-free healthy margins, irradiation therapy, and/or chemotherapy are all treatment modalities that increase in severity along with the extent, staging, and behavior of the tumor itself [27].

The available specialized testing, such as computed tomography (CT) scan and magnetic resonance imaging (MRI) in radiology, may indirectly contribute to detection and treatment delay owing to financial burden, discomfort, and avoidance by the patient, or even owing to a potential lack of instrumentation or specialized personnel in rural areas. A safe, cost-effective, comfortable for the patient, universally accessible testing is needed in order to be possible for it to be performed routinely worldwide. Ideally, specialized personnel or equipment should not be needed for sample collection. With this directive, saliva is being investigated as a means of detection and diagnosis for different types of oncologic entities.

For instance, oral squamous cell carcinoma (OSCC), the most common oral cavity malignancy, has been correlated with the level of expression of certain proteins that can be detected in the saliva $[29,30]$. Immunohistochemical staining and comparison of resected tumor tissue and non-tumor tissue of the same patient has been used as a method to further verify an increased level of proposed biomarkers in the tumor tissues [30]. Of great clinical significance, the use of liquid chromatography/mass spectroscopy for analysis of salivary metabolites presented $94.6 \%$ sensitivity and $84.4 \%$ specificity for the distinction between OSCC and the most frequent oral premalignant lesion known as leukoplakia. The same technique presented $86.5 \%$ sensitivity and $82.4 \%$ specificity when OSCC was compared to controls [31]. In comparison, in a study that used NMR for oral or laryngeal squamous cell carcinoma, the sensitivity $(87.5 \%)$ and specificity $(93.3 \%)$ were higher [13]. NMR has been found to contribute in the salivary metabolomic analysis and monitoring of sarcoidosis as well (Table 1) [14]. The current need for further involvement of nanoscale testing techniques in oncologic diagnosis and investigation is now emphasized, following the contemporary and rapidly evolving literature on biomarkers [32].

\section{Proposed Saliva Collection Timing Protocol in the Dental Clinical Setting}

Saliva testing begins with collection of the specimen. The saliva collection protocol should consist of the collection methodology, as well as the timing of initial and subsequent collections for the monitoring of health and/or pathology. Regarding the saliva collection methodology, certain recommendations have been proposed in the literature in order to minimize the influence of other factors and external variants, as well as to increase reproducibility. Saliva collection has been proposed to be performed $24 \mathrm{~h}$ after dental treatment to avoid blood contamination, and $12 \mathrm{~h}$ after the use of alcohol, nicotine, caffeine, or medications (if medically feasible) $[9,17]$. Morning collection is widely preferred in order to minimize the effect of the circadian rhythm. At least one hour $[4,8,9]$, two hours $[3-6,10,11,15]$, or complete refrain upon awaking [12,21] from oral activities, including eating, drinking, and oral hygiene, was found in the literature (Table 1). Unstimulated whole saliva with passive expectoration in a sterile container is widely accepted in order to eliminate potential variants $[3-9,11-13,15,25]$. When passive expectoration is not feasible, the use of cotton absorbent materials is not recommended [24,25]. Instead, a pipette has been used to collect the unstimulated whole saliva from the floor of the mouth for early childhood $[4,5]$. 
The second aspect of the saliva collection procedure is the timing, regarding when and how often it should be performed. The timing of collection in relation to the health status of an individual would play a principal role in the early identification of an underlying pathology, but also in the follow-up monitoring. Here, we propose a saliva sampling schedule template that correlates with routine health appointments in dental clinics. The biofluid sampling schedule is determined by the individual oral health assessment, as completed during the clinical appointments (Table 2). In general, follow-up clinical appointments are determined based on the individual medical assessment, treatment planning, prognosis, nature of intervention needed (e.g., non-intervention monitoring vs. pharmaceutical intervention vs. surgical), and so on. For instance, a surgical intervention involving soft and osseous tissue is often followed by an immediate post-operative appointment to evaluate the initial healing of soft tissue, and by subsequent appointments at 3-6 months, in accordance with osseous remodeling rates $[8,33]$. In our template (Table 2 ), the clinician would evaluate each oral structure (far left vertical column) regarding the presence or absence (WNL: within normal limits) of pathological findings. For instance, the 'WNL' circle will be marked for each oral structure with the absence of pathology. In the case of presence or indication of pathology for an oral structure, the clinician would indicate the need and the nature of intervention by marking one of the other four columns (non-intervention monitoring to surgical intervention osseous tissue). The need and nature for intervention increases in our table from left to right, and the saliva sampling frequency (yellow columns) follows as well. Any single evaluated structure that needs more 'invasive' or more 'frequent' monitoring will determine the final biofluid sampling schedule for the patient. This will be demonstrated on the completed Table 2 by the furthest to the right marked category of the oral health assessment. The initial biofluid sampling schedule may be altered as the individual health evaluation is reassessed at follow-up appointments.

We theoretically estimate that during the proposed time intervals, a significant change on saliva metabolites may occur that would be of interest to investigate, as it may reflect important information regarding the health status and changes of the oral environment. For instance, saliva profiling at these follow-up intervals may provide information regarding the physiologic tissue remodeling, tissue healing versus progressive destruction, pharmaceutical intervention effect and efficiency, stabilization of a condition after intervention, and thus confirmation or rejection of the selected intervention. However, it was attempted to make the proposed sample collection regime as versatile and universal as possible. It needs to be tested experimentally, and modified as needed, in order for clinicians to use it along with the individualized medical assessment of the patient for early oral health diagnosis and monitoring.

Table 2. Proposed oral biofluid sampling schedule. WNL, within normal limits.

\begin{tabular}{|c|c|c|c|c|c|}
\hline \multicolumn{2}{|c|}{$\begin{array}{l}\text { Oral Health } \\
\text { Assessment: }\end{array}$} & $\begin{array}{c}\text { NO } \\
\text { INTERVENTION } \\
\text { Monitoring } \\
\end{array}$ & $\begin{array}{l}\text { NON-SURGICAL } \\
\text { INTERVENTION }\end{array}$ & $\begin{array}{c}\text { SURGICAL } \\
\text { INTERVENTION } \\
\text { Soft or Dental Tissue }\end{array}$ & $\begin{array}{l}\text { SURGICAL } \\
\text { INTERVENTION } \\
\text { Osseous Tissue }\end{array}$ \\
\hline \multicolumn{6}{|l|}{ DENTAL } \\
\hline \multicolumn{6}{|c|}{ PERIODONTAL } \\
\hline \multicolumn{6}{|l|}{ MUCOSA } \\
\hline \multicolumn{6}{|l|}{ TONGUE } \\
\hline \multicolumn{6}{|l|}{ OSSEOUS } \\
\hline \multicolumn{6}{|l|}{ SALIVA } \\
\hline \multicolumn{6}{|c|}{ Biofluid Sampling Schedule: } \\
\hline & $\begin{array}{c}\text { Initial Appointment } \\
- \\
- \\
12 \text { mo } \\
- \\
24 \text { mo } \\
\text { per annum }\end{array}$ & $\begin{array}{c}\text { Initial } \\
\text { Appointment } \\
- \\
6 \mathrm{mo} \\
12 \mathrm{mo} \\
- \\
24 \mathrm{mo} \\
\text { per annum }\end{array}$ & $\begin{array}{c}\text { Initial } \\
\text { Appointment } \\
2-8 \text { wks } \\
6 \text { mo post-op } \\
12 \text { mo post-op } \\
- \\
24 \text { mo post-op } \\
\text { per annum }\end{array}$ & $\begin{array}{c}\text { Initial Appointment } \\
6-8 \text { wks } \\
6 \text { mo post-op } \\
12 \text { mo post-op } \\
- \\
24 \text { mo post-op } \\
\text { per annum }\end{array}$ & $\begin{array}{c}\text { Initial } \\
\text { Appointment } \\
4 \text { mo post-op } \\
6 \text { mo post-op } \\
12 \text { mo post-op } \\
18 \text { mo post-op } \\
24 \text { mo post-op } \\
\text { per annum }\end{array}$ \\
\hline
\end{tabular}




\section{Future Application on Sjögren's Syndrome}

A particular medical area that urgently calls for further development of the current clinical testing and evaluation methodology is Sjögren's syndrome. Sjögren's syndrome is a complex, multisystem autoimmune disease, which results in reduced production of saliva (xerostomia) and tears (xerophtalmia). Its variability in presentation and symptoms imposes a great challenge for early detection, diagnosis, staging, and evaluation of the effectiveness of treatment. Biomarkers and saliva sampling have been emphasized for their potential in non-invasive diagnosis. There is still a great need for further research in order to establish a universal, reliable, non-invasive method with high sensitivity and specificity for each subgroup of this syndrome [34]. Recently, metabolomics analyses to identify salivary and lacrimal biomarkers have been attempted using mass spectroscopy with liquid or gas chromatography $[35,36]$. To our knowledge, NMR has not yet been employed for further exploration of the biomarkers' potential in the diagnosis and monitoring of Sjögren's syndrome. Future studies could contribute significantly to the understanding, early intervention, and effective therapy of the syndrome.

Moreover, even in the areas of oral and dental pathology, the published data remain limited. Salivary testing needs to be further explored and standardized in order for its development as a widely available and established testing for the identification and monitoring of oral conditions. In addition, its demonstrated potential for testing the effectiveness of a dental or periodontal therapy will enormously facilitate and guide the dental health care $[5,8]$. Furthermore, it would be of a great value to explore the potential of salivary diagnostic testing in areas such as infectious or autoimmune conditions, endocrinology, nephrology, cardiology, and metabolic conditions.

\section{Conclusions and Perspectives}

Non-invasiveness is of high significance in the clinical setting as it reduces and/or eliminates the psychological and the physical stress caused by the testing procedure itself. As a result, not only are the patients more compliant, and thus the diagnosis and monitoring of a condition are not delayed owing to fear or avoidance of the procedure, but it also allows frequent evaluation even for individuals with health conditions that would preclude or complicate any surgical testing procedure. Furthermore, a testing or analysis procedure that is inexpensive, accessible, and does not necessitate specialized personnel, as in the case of saliva collection, would allow its use worldwide as a universal and standard of care clinical protocol. As a result, health would be further promoted, and relapses or compromised quality of life after treatment would be further reduced because of the early detection and intervention. NMR presents a great potential to compliment the current research on biomarkers as it can detect nano-characteristics of isolated molecules in the provided bio-sample. Combined with saliva testing, early detection and intervention could be greatly promoted.

The standardization of the methodology is of high importance. The significant inter-study variability has been pointed out regarding saliva sample storage, preparation, and NMR quantification method, in contrast to the established methodology for other biofluids (e.g., plasma, urine) [19]. For the clinical application of saliva testing as a diagnostic method, specific sampling collection indications and guidelines need to be established as well, which should be based on the specific health condition that is under investigation. Here, we attempt to propose such a clinical protocol based on routine follow-up regimens for oral health.

To sum up, nuclear magnetic resonance in combination with saliva analysis has provided important information regarding dental and periodontal health, as well as oncologic pathology of oral tissues. However, it has not yet been explored up to its potential, and future studies are needed to further identify salivary biomarkers for early diagnosis of not only oral diseases, but also distant sites.

Author Contributions: Conceptualization, investigation, and data collection, A.K. and D.K.; writing-original draft preparation, A.K. and D.K.; writing-review and editing, D.K. and A.K.; visualization, D.K. and A.K.; supervision, D.K.; project administration, D.K. All authors have read and agreed to the published version of the manuscript.

Funding: This research received no external funding. 
Conflicts of Interest: The authors declare no conflict of interest.

\section{References}

1. Mikkonen, J.J.W.; Singh, S.P.; Herrala, M.; Lappalainen, R.; Myllymaa, S.; Kullaa, A.M. Salivary metabolomics in the diagnosis of oral cancer and periodontal diseases. J. Periodontal Res. 2016, 51, 431-437. [CrossRef]

2. Kaczor-Urbanowicz, K.E.; Martin Carreras-Presas, C.; Aro, K.; Tu, M.; Garcia-Godoy, F.; Wong, D.T. Saliva diagnostics-Current views and directions. Exp. Biol. Med. (Maywood) 2016, 242, 459-472. [CrossRef]

3. Silwood, C.J.L.; Lynch, E.J.; Seddon, S.; Sheerin, A.; Claxson, A.W.D.; Grootveld, M.C. 1H-NMR analysis of microbial-derived organic acids in primary root carious lesions and saliva. NMR Biomed. 1999, 12, 345-356. [CrossRef]

4. Da Silva, L.P.; da Silva Bastos, V.D.A.; da Silva Fidalgo, T.K.; de Oliveira, C.M.; Pomarico, L.; Valente, A.P.; Freitas-Fernandes, L.B.; Pomari, I. Oral Health of Babies and Mothers during the Breastfeeding Period. J. Clin. Diagn. Res. 2019, 13,1-5. [CrossRef]

5. Fidalgo, T.K.S.; Freitas-Fernandes, L.B.; Almeida, F.C.L.; Valente, A.P.; Souza, I.P.R. Longitudinal evaluation of salivary profile from children with dental caries before and after treatment. Metabolomics 2014, 11, 583-593. [CrossRef]

6. Fidalgo, T.K.S.; Freitas-Fernandes, L.B.; Angeli, R.; Muniz, A.M.S.; Gonsalves, E.; Santos, R.; Nadal, J.; Almeida, F.C.L.; Valente, A.P.; Souza, I.P.R. Salivary metabolite signatures of children with and without dental caries lesions. Metabolomics 2012, 9, 657-666. [CrossRef]

7. Singh, M.P.; Saxena, M.; Saimbi, C.S.; Siddiqui, M.H.; Roy, R. Post-periodontal surgery propounds early repair salivary biomarkers by $1 \mathrm{H}$ NMR based metabolomics. Metabolomics 2019, 15, 1-12. [CrossRef] [PubMed]

8. Romano, F.; Meoni, G.; Manavella, V.; Baima, G.; Mariani, G.M.; Cacciatore, S.; Tenori, L.; Aimetti, M. Effect of non-surgical periodontal therapy on salivary metabolic fingerprint of generalized chronic periodontitis using nuclear magnetic resonance spectroscopy. Arch. Oral Biol. 2019, 97, 208-214. [CrossRef] [PubMed]

9. Romano, F.; Meoni, G.; Manavella, V.; Baima, G.; Tenori, L.; Cacciatore, S.; Aimetti, M. Analysis of salivary phenotypes of generalized aggressive and chronic periodontitis through nuclear magnetic resonance-based metabolomics. J. Periodontol. 2018, 89, 1452-1460. [CrossRef] [PubMed]

10. Rzeznik, M.; Triba, M.N.; Levy, P.; Jungo, S.; Botosoa, E.; Duchemann, B.; Le Moyec, L.; Bernaudin, J.-F.; Savarin, P.; Guez, D. Identification of a discriminative metabolomic fingerprint of potential clinical relevance in saliva of patients with periodontitis using $1 \mathrm{H}$ nuclear magnetic resonance (NMR) spectroscopy. PLoS ONE 2017, 12, 1-16. [CrossRef]

11. Singh, M.P.; Saxena, M.; Saimbi, C.S.; Arif, J.M.; Roy, R. Metabolic profiling by 1H NMR spectroscopy of saliva shows clear distinction between control and diseased case of periodontitis. Metabolomics 2017, 13, 1-11. [CrossRef]

12. Aimetti, M.; Cacciatore, S.; Graziano, A.; Tenori, L. Metabonomic analysis of saliva reveals generalized chronic periodontitis signature. Metabolomics 2011, 8, 465-474. [CrossRef]

13. Mikkonen, J.; Singh, S.; Akhi, R.; Salo, T.; Lappalainen, R.; Gonzalez-Arriagada, W.; Ajudarte Lopes, M.R.; Kullaa, A.; Myllymaa, S. Potential role of nuclear magnetic resonance spectroscopy to identify salivary metabolite alterations in patients with head and neck cancer. Oncol. Lett. 2018, 16, 6795-6800. [CrossRef] [PubMed]

14. Duchemann, B.; Triba, M.N.; Guez, D.; Rzeznik, M.; Savarin, P.; Nunes, H.; Valeyre, D.; Bernaudin, J.-F.; Le Moyec, L. Nuclear magnetic resonance spectroscopic analysis of salivary metabolome in sarcoidosis. Sarcoidosis Vasc. Diffus. Lung Dis. 2016, 33, 10-16.

15. García-Villaescusa, A.; Morales-Tatay, J.M.; Monleón-Salvadó, D.; González-Darder, J.M.; Bellot-Arcis, C.; Montiel-Company, J.M.; Almerich-Silla, J.M. Using NMR in saliva to identify possible biomarkers of glioblastoma and chronic periodontitis. PLoS ONE 2018, 13, 1-12. [CrossRef] [PubMed]

16. Human Salivary Proteome Wiki. Available online: https://salivaryproteome.nidcr.nih.gov/public/index.php/ Main_Page (accessed on 30 March 2020).

17. Beale, D.; Jones, O.; Karpe, A.; Dayalan, S.; Oh, D.; Kouremenos, K.; Ahmed, W.; Palombo, E. A Review of Analytical Techniques and Their Application in Disease Diagnosis in Breathomics and Salivaomics Research. Int. J. Mol. Sci. 2017, 18, 24. [CrossRef] [PubMed]

18. Nonaka, T.; Wong, D.T.W. Saliva-Exosomics in Cancer: Molecular Characterization of Cancer-Derived Exosomes in Saliva. Enzymes 2017, 42, 125-151. 
19. Gardner, A.; Parkes, H.G.; Carpenter, G.H.; So, P.-W. Developing and Standardizing a Protocol for Quantitative Proton Nuclear Magnetic Resonance (1H NMR) Spectroscopy of Saliva. J. Proteome Res. 2018, 17, 1521-1531. [CrossRef]

20. Novoa-Carballal, R.; Fernandez-Megia, E.; Jimenez, C.; Riguera, R. NMR methods for unravelling the spectra of complex mixtures. Nat. Prod. Rep. 2011, 28, 78-98. [CrossRef]

21. Silwood, C.J.L.; Lynch, E.; Claxson, A.W.D.; Grootveld, M.C. 1H and (13)C NMR spectroscopic analysis of human saliva. J. Dent. Res. 2002, 81, 422-427. [CrossRef]

22. Dunn, W.B.; Broadhurst, D.I.; Atherton, H.J.; Goodacre, R.; Griffin, J.L. Systems level studies of mammalian metabolomes: The roles of mass spectrometry and nuclear magnetic resonance spectroscopy. Chem. Soc. Rev. 2011, 40, 387-426. [CrossRef] [PubMed]

23. Emwas, A.-H.; Roy, R.; McKay, R.T.; Tenori, L.; Saccenti, E.; Gowda, G.A.N.; Raftery, D.; Alahmari, F.; Jaremko, L.; Jaremko, M.; et al. NMR Spectroscopy for Metabolomics Research. Metabolites 2019, 9, 2628. [CrossRef] [PubMed]

24. Pereira, J.L.; Duarte, D.; Carneiro, T.J.; Ferreira, S.; Cunha, B.; Soares, D.; Costa, A.L.; Gil, A.M. Saliva NMR metabolomics: Analytical issues in pediatric oral health research. Oral Dis. 2019, 8, 1-10. [CrossRef] [PubMed]

25. Granger, D.A.; Kivlighan, K.T.; Fortunato, C.; Harmon, A.G.; Hibel, L.C.; Schwartz, E.B.; Whembolua, G.-L. Integration of salivary biomarkers into developmental and behaviorally-oriented research: Problems and solutions for collecting specimens. Physiol. Behav. 2007, 92, 583-590. [CrossRef]

26. Unger-Saldaña, K.; Miranda, A.; Zarco-Espinosa, G.; Mainero-Ratchelous, F.; Bargalló-Rocha, E.; Lázaro-León, J.M. Health system delay and its effect on clinical stage of breast cancer: Multicenter study. Cancer 2015, 121, 2198-2206. [CrossRef]

27. Chaukar, D.A.; Walvekar, R.R.; Das, A.K.; Deshpande, M.S.; Pai, P.S.; Chaturvedi, P.; Kakade, A.; D'Cruz, A.K. Quality of life in head and neck cancer survivors: A cross-sectional survey. Am. J. Otolaryngol. 2009, 30, 176-180. [CrossRef]

28. Kraaijenga, S.A.C.; Oskam, I.M.; van der Molen, L.; Hamming-Vrieze, O.; Hilgers, F.J.M.; van den Brekel, M.W.M. Evaluation of long term (10-years+) dysphagia and trismus in patients treated with concurrent chemo-radiotherapy for advanced head and neck cancer. Oral Oncol. 2015, 51, 787-794. [CrossRef]

29. Jou, Y.J.; Hua, C.H.; Lin, C.D.; Lai, C.H.; Huang, S.H.; Tsai, M.H.; Kao, J.Y.; Lin, C.W. S100A8 as potential salivary biomarker of oral squamous cell carcinoma using nanoLC-MS/MS. Clin. Chim. Acta 2014, 436, 121-129. [CrossRef]

30. Katakura, A.; Yamamoto, N.; Sakuma, T.; Sugahara, K.; Onda, T.; Noguchi, S.; Shibahara, T. A screening test for oral cancer using saliva samples: Proteomic analysis of biomarkers in whole saliva. J. Oral Maxillofac. Surg. Med. Pathol. 2015, 27, 1-5. [CrossRef]

31. Wei, J.; Xie, G.; Zhou, Z.; Shi, P.; Qiu, Y.; Zheng, X.; Chen, T.; Su, M.; Zhao, A.; Jia, W. Salivary metabolite signatures of oral cancer and leukoplakia. Int. J. Cancer 2011, 129, 2207-2217. [CrossRef]

32. Cheng, J.; Nonaka, T.; Wong, D. Salivary Exosomes as Nanocarriers for Cancer Biomarker Delivery. Materials 2019, 12, 5593. [CrossRef] [PubMed]

33. Hansson, S.; Halldin, A. Alveolar ridge resorption after tooth extraction: A consequence of a fundamental principle of bone physiology. J. Dent. Biomech. 2012, 3, 1-8. [CrossRef] [PubMed]

34. Jonsson, R.; Brokstad, K.A.; Jonsson, M.V.; Delaleu, N.; Skarstein, K. Current concepts on Sjögren's syndrome-Classification criteria and biomarkers. Eur. J. Oral Sci. 2018, 126, 37-48. [CrossRef]

35. Aqrawi, L.A.; Galtung, H.K.; Vestad, B.; Ovstebo, R.; Thiede, B.; Rusthen, S.; Young, A.; Guerreiro, E.M.; Utheim, T.P.; Chen, X.; et al. Identification of potential saliva and tear biomarkers in primary Sjögren's syndrome, utilising the extraction of extracellular vesicles and proteomics analysis. Arthritis Res. Ther. 2017, 19, 1-15. [CrossRef] [PubMed]

36. Kageyama, G.; Saegusa, J.; Irino, Y.; Tanaka, S.; Tsuda, K.; Takahashi, S.; Sendo, S.; Morinobu, A. Metabolomics analysis of saliva from patients with primary Sjögren's syndrome. Clin. Exp. Immunol. 2015, 182, 149-153. [CrossRef]

(C) 2020 by the authors. Licensee MDPI, Basel, Switzerland. This article is an open access article distributed under the terms and conditions of the Creative Commons Attribution (CC BY) license (http://creativecommons.org/licenses/by/4.0/). 